\title{
Contraception in the COVID-19 pandemic: recommendations from the Korean society of contraception and reproductive health
}

Jae Hoon Lee, MD', Jae Yen Song, MD, PhD², Kyong Wook Yi, MD, PhD ${ }^{3}$, Jin Ju Kim, MD, PhD ${ }^{4}$, Kyu Ri Hwang, MD, PhD ${ }^{5}$, Jung-Ho Shin, MD, PhD ${ }^{3}$, Ji Young Lee, MD, PhD ${ }^{6}$, Hee Dong Chae, MD, PhD ${ }^{7}$

Department of Obstetrics and Gynecology, ${ }^{1}$ Gangnam Severance Hospital, Yonsei University College of Medicine, ${ }^{2}$ Seoul St. Mary's Hospital, College of Medicine, The Catholic University of Korea, ${ }^{3}$ Korea University College of Medicine, ${ }^{4}$ Seoul National University Hospital Healthcare System Gangnam Center, ${ }^{5}$ SMG-SNU Boramae Medical Center, ${ }^{6}$ Konkuk University School of Medicine, ${ }^{7}$ Asan Medical Center, University of Ulsan College of Medicine, Seoul, Korea

Coronavirus disease 2019 (COVID-19) is associated with a systemic inflammatory response that activates coagulation in symptomatic patients. In addition, a rare form of thrombosis has been reported in people who received the COVID-19 vaccine, most of whom were women younger than 50 years of age. Considering that hormonal contraceptive methods widely used by women of childbearing age increase the risk of thrombosis, the development of guidelines for the use of hormonal contraceptives in the era of the COVID-19 pandemic is necessary. In this context, the Korean Society of Contraception and Reproductive Health provides guidelines for issues regarding contraception and reproductive health during the pandemic.

Keywords: COVID-19; COVID-19 vaccines; Contraception; Contraceptives, oral, combined; Long-acting reversible contraception

\section{Introduction}

As the coronavirus disease 2019 (COVID-19) outbreak rages, its impact is being felt in all areas of healthcare. Breakthrough infections caused by the Omicron variant (B.1.1.529) of the severe acute respiratory syndrome coronavirus 2 (SARS-CoV-2) are becoming a global problem, and doubts are growing as to whether the vaccine will be a pandemic game-changer. In addition to the overburdening of the healthcare system due to the increased number of patients with confirmed COVID-19, conflicts are arising over the efficient distribution of medical resources. Since most medical resources are currently devoted to securing isolation beds and medical services for those vulnerable to COVID-19, there are growing social concerns about the disruption of essential medical services.

The World Health Organization (WHO) conducted a survey among the Ministry of Health officials in five WHO regions between May and July 2020 to assess the impact of the COVID-19 pandemic on up to 25 essential health services in 105 countries [1]. The survey revealed that almost every country (90\%) experienced a disruption of essential medical services to some extent, with greater disruptions reported in lowand middle-income countries as opposed to those reported

Received: 2021.10.22. Revised: 2021.12.19. Accepted: 2021.12.23.

Corresponding author: Ji Young Lee, MD, PhD

Department of Obstetrics and Gynecology, Konkuk University

School of Medicine, 120 Neungdong-ro, Gwangjin-gu, Seoul

05030, Korea

E-mail: jylee@kuh.ac.kr

https://orcid.org/0000-0002-0682-6685

Kyong Wook Yi and Kyu Ri Hwang have been an Editorial Board of Obstetrics \& Gynecology Science; however, they are not involved in the peer reviewer selection, evaluation, or decision process of this article. Otherwise, no other potential conflicts of interest relevant to this article were reported.

Articles published in Obstet Gynecol Sci are open-access, distributed under the terms of the Creative Commons Attribution Non-Commercial License (http://creativecommons. org/licenses/by-nc/3.0/) which permits unrestricted non-commercial use, distribution, and reproduction in any medium, provided the original work is properly cited.

Copyright $\odot 2022$ Korean Society of Obstetrics and Gynecology 


\section{Obstetrics \& Gynecology Science}

Vol. 65, No. 2, 2022

in high-income countries. Among the 25 essential health services, the most frequently disrupted included routine immunization services (70\%), noncommunicable disease diagnosis and treatment (69\%), and family planning and contraception (68\%). History tells us that during previous massive infectious outbreaks, such as the recent Ebola epidemic in the Democratic Republic of Congo, Sierra Leone, and Liberia, contraception healthcare dropped dramatically with stockouts of contraceptive methods [2]. The same scenarios are observed in the current COVID-19 pandemic. Furthermore, recent reports indicated that social distancing measures may increase the risk of intimate partner violence by limiting the ability of victims to distance themselves from their abusers, or to access external support, which may result in an increase in unintended pregnancies $[3,4]$.

Meanwhile, thrombotic events that are associated with increased disease severity and worse clinical outcomes frequently occur in patients with COVID-19 [5,6]. SARS-CoV2-induced complement hyperactivation, endothelial dysfunction, and cytokine storms have a prothrombotic effect. These conditions may lead to acute respiratory distress syndrome, hypercoagulation, and disseminated intravascular coagulation [5]. Consequently, there is growing concern regarding the use of oral contraceptives containing both estrogen and progestin. Moreover, a rare form of thrombosis has been reported in people who received the COVID-19 vaccine, most of whom were women younger than 50 years of age $[7,8]$. Considering that combined oral contraceptives (COCs) are over-the-counter drugs in South Korea and are widely used by women of childbearing age, there is a need for the development of guidelines on the use of COCs in the era of the COVID-19 pandemic. In this context, the Korean Society of Contraception and Reproductive Health (KSCRH) provides guidelines for issues regarding contraception and reproductive health during the pandemic.

\section{Contraception in the era of COVID-19}

\section{Recommendations}

A. During the COVID-19 pandemic, attempting pregnancy, spontaneous pregnancy, or ART can be continued.

B. Considering the increased likelihood of exposure to COVID-19 and limited access to essential healthcare services, contraception provides several advantages during the pan- demic.

C. Because the risk of thrombosis with the use of low-dose COCs is significantly lower than that during pregnancy (the relative risk of venous thrombosis is 2 for low-dose COCs and 12 for pregnancy), the benefits of avoiding pregnancy outweigh the thrombotic risk of COCs in fertile women.

D. Most contraceptive methods are safe to use by the majority of patients, and the use of COCs should follow the US Medical Eligibility Criteria provided by the CDC.

E. Considering the current shortage of COCs, limited access to medical services, and the thrombosis risk associated with COVID-19, LARCs provide several advantages.

In April 2020, during the early days of the COVID-19 pandemic, professional organizations, including the European Society of Human Reproduction and Embryology (ESHRE) and the American Society for Reproductive Medicine (ASRM), provided emergency guidelines on how to handle fertility treatment during the pandemic $[9,10]$. As can be deduced from the title of the editorial in Human Reproduction, "Safety first-assisted human reproduction second," temporary interruption of assisted reproductive technology (ART) was recommended because the risk of contamination and infection with SARS-CoV-2 during fertility treatment was not accurately known [11].

Subsequently, transcriptomic and proteomic analyses showed that angiotensin-converting enzyme 2 (ACE2) and transmembrane protease serine 2 , which are necessary for SARS-CoV-2 invasion, are not expressed in spermatozoa or the ovarian granulosa cells of the ovary [12]. Additionally, it was reported that SARS-CoV-2 is not commonly detected in semen [13]. Reports have shown that vertical transmission of COVID-19 does not occur routinely in pregnant women, and the possibility of acquiring COVID-19 during the course of ART is not higher than that with natural conception [14]. In September 2020, the ESHRE, ASRM, and International Federation of Fertility Societies released a joint statement that recommended continuing reproductive care during the COVID-19 pandemic [15].

Nevertheless, the advantages of birth spacing have been well documented [16]. Avoiding a pregnancy during the pandemic has benefits for women not only on a personal level, but also from a public health perspective to avoid adding to the overburdened health systems [17]. This is especially true given the increased likelihood of exposure to COVID-19 during pregnancy with limited access to healthcare services. 


\section{Obstetrics \& Gynecology Science}

Jae Hoon Lee, et al. Contraception in the COVID-19 pandemic

Most contraceptive methods are safe for use by the majority of patients, and the Centers for Disease Control and Prevention (CDC) has provided the United States Medical Eligibility Criteria for Contraceptive Use (US MEC) to assess whether patients have any characteristics or medical conditions restricting the use of a specific contraceptive method [18]. The US MEC are equally applicable to patients during the COVID-19 pandemic [19].

The risk of thrombosis increases during the first 3 months of using COCs and then decreases sharply [20-22]. The increased risk is related to the dosage of estrogen contained in the COCs and is also affected by the type of progestin $[23,24]$. However, thrombosis risk associated with taking low-dose COCs is significantly lower than that associated with pregnancy (the relative risk of venous thrombosis is two for lowdose COCs and 12 for pregnancy) $[25,26]$. Therefore, the benefit of avoiding pregnancy outweighs the thrombotic risk of COCs in fertile women. In a recent systematic review of 1,063 pregnant women with COVID-19, three women had thromboembolic complications (0.28\%) [27]. Considering that the absolute risk of thromboembolic complications in pregnant women without COVID-19 is only $0.1 \%$, the absolute risk of thrombosis may not be high in women with $\mathrm{CO}$ VID-19 infection taking COCs [28]. Accordingly, the use of COCs may be justified in women taking oral contraceptives for therapeutic purposes other than contraception.

In fact, a significant number of COCs have been out of stock since the second half of 2020 in South Korea, while the oral contraceptive shortage is still ongoing. In 2020, the United Nations Population Fund predicted that most countries will experience stockouts of one or more modern contraception methods, including implants, intramuscular and subcutaneous depot medroxyprogesterone acetate, copper intrauterine devices, COCs, progestin-only pills, and condoms. Considering the current shortage of COCs, the likelihood of limited access to medical services in the future, and the risk of thrombosis with COVID-19, long-acting reversible contraceptives (LARCS) may be of particular value in women starting a new contraceptive method or changing the method according to the recommendations of the International Federation of Gynecology and Obstetrics [29].

\section{Contraception in women with COVID-19}

\section{Recommendations}

A. COCs can be used in women with mild to moderate symptoms of confirmed or suspected COVID-19.

B. Women should stop taking COCs and consider using prophylactic anticoagulants if they are severely ill with persistent respiratory symptoms or hospitalized due to suspected or confirmed COVID-19.

C. In women who have a hormonal intrauterine device or subcutaneous implant, removing the contraceptive device is not necessary, even if they have suspected or confirmed COVID-19.

It appears that COVID-19 is uniquely prothrombotic compared with other severe viral respiratory pneumonias [5]. Pulmonary embolism and deep vein thrombosis are the most frequently noted thrombotic events in COVID-19, with a reported incidence of 20 to 30\% [6]. In a Dutch cohort of 184 patients that were admitted in the intensive care unit with COVID-19, the cumulative incidence of large-vessel thrombotic events was 49\%, despite thromboprophylaxis [30]. Moreover, major vascular thrombosis, such as stroke, has been reported in young patients aged $<50$ years who have even fewer risk factors for thrombosis [31]. Therefore, there is a concern that COCs, widely used in women of childbearing age, may increase the coagulation factors and risk of thromboembolic events in women with COVID-19.

A recent publication has recommended that peri- and postmenopausal women immediately terminate exogenous hormone treatment after becoming infected with SARS-CoV-2 [32]. However, this recommendation was based on expert opinion and not on real data. To date, no report has documented that hormonal contraceptive use during COVID-19 is associated with a worse prognosis [33]. In addition, there are data supporting the fact that female hormones may potentially help, or at least do not worsen the clinical course of the disease [34-36]. Although the mechanisms by which sex steroid hormones are involved in the response to SARS-CoV-2 infection are still unclear, ACE2 expression by host cells and several immune responses are known to be regulated by estrogen [37].

According to a recent systematic review, the risk of thrombosis in pregnant women with COVID-19 is $0.28 \%$, slightly higher than $0.1 \%$, which is the absolute risk of thromboembolic complications in pregnant women without COVID-19 


\section{Obstetrics \& Gynecology Science}

Vol. 65, No. 2, 2022

[27]. Considering that the relative risk of thrombosis with low-dose COCs is approximately one-sixth of that of pregnancy, the absolute risk of thrombosis due to COCs when associated with COVID-19 is not considered to be high. Moreover, the risk of thrombosis increases within the first 3 months of initiating COCs, and then decreases sharply. The risk of increase in thrombosis occurs only during the first year [20-22]. However, in severely ill women with persistent respiratory symptoms, COCs should be discontinued. Patients with COVID-19 develop a pro-coagulative state directly related to disease severity [38]. The contraceptive and noncontraceptive benefits of COCs do not outweigh the potential risk of thrombosis in patients with severe COVID-19. In the case of a hormonal intrauterine device or subcutaneous implant, removing the contraceptive device does not appear to be necessary. Progestin alone does not increase the risk of thrombosis at the dose used for contraception [39], and no study has reported the thrombophilic effect of progestin via an implant or intrauterine system [40]. Therefore, progestinreleasing intrauterine devices or subcutaneous implants are considered safe with respect to the risk of thrombosis.

\section{COVID-19 vaccine and contraception}

\section{Recommendations}

A. Despite the rare thrombotic side effects of the COVID-19 vaccine in young women under the age of 50 years, the benefits of the vaccine outweigh the risks. Therefore, the KSCRH recommends vaccination for women of childbearing age.

B. The KSCRH recommends vaccination for pregnant women and women taking COCs. The type and timing of the vaccine can be individualized according to the comorbidities and systemic conditions of the individuals.

C. In women using COCs, the use of COCs does not require a delay in vaccination, and discontinuation of COCs is not necessary before or after vaccination.

D. COCs can be initiated at any time regardless of vaccination status. However, in women with risk factors for thrombosis who are planning contraception immediately after vaccination, use of LARCs (intrauterine or subcutaneous contraceptive implants) may minimize the risk of thrombosis.

Recently, post-vaccine thrombosis cases have been reported in women who were administered COVID-19 vaccine based on adenoviral vectors. On April 7, 2021, the safety commit- tee of the European Medicines Agency (EMA) concluded that unusual blood clots with low blood platelets should be listed as a very rare side effect of the AstraZeneca COVID-19 vaccine. Nevertheless, the EMA confirmed that the overall benefit-risk profile of the vaccine remains positive, and recommended the use of the AstraZeneca COVID-19 vaccine [11]. In the same month, the Food and Drug Administration and $C D C$ recommended a temporary pause in the use of the Janssen COVID-19 vaccine after six thrombosis cases involving the cerebral venous sinuses or other atypical locations (splanchnic vein in the abdomen), along with thrombocytopenia were reported [12]. Although the pathophysiology is not fully understood, vaccination is likely to induce the formation of antibodies against platelet antigens as part of the inflammatory reaction and immune stimulation $[41,42]$. These antibodies subsequently cause massive platelet activation via the Fc receptor, similar to heparin-induced thrombocytopenia.

The incidence of thrombosis following vaccination is seven cases per 1 million people, which is estimated to be 1.4 times the natural incidence rate [43]. In particular, many thrombosis cases occurred in women under the age of 50 years. Since COCs are over-the-counter drugs in South Korea, and are widely used by women of childbearing age, there is a concern that these rare side effects of the vaccine may occur more frequently in women taking COCs. However, COCs cause blood clots by a different mechanism than that of the COVID-19 vaccines. The vaccine mechanism involves enhancing the function of platelets, specifically by increasing the plasma fibrinogen level and coagulation activity that mainly occurs at typical locations (i.e., leg vein thrombosis and pulmonary embolism) [44]. Currently, there is no evidence that vaccines based on adenoviral vectors causes more thromboses at typical locations [45].

The risk of thrombosis associated with COVID-19 vaccines is significantly lower than that associated with COVID-19, and the social benefits of vaccination are vast; therefore, several organizations, including the CDC, National Health Service (London, UK), EMA, and Korea Centers for Disease Control and Prevention (KDCA), have recommended the continuation of vaccination. In particular, in October 2021, the KDCA began to provide opportunities for vaccination of pregnant women, and strongly recommended that pregnant women should be vaccinated [46]. The KDCA has also recommended vaccination (Janssen and mRNA vaccines) for all 


\section{Obstetrics \& Gynecology Science}

Jae Hoon Lee, et al. Contraception in the COVID-19 pandemic

people aged 12 years and older [47]. The WHO is more conservative about vaccination during pregnancy, recommending the use of the COVID-19 vaccine in pregnant women only if the benefits of vaccination outweigh the potential risks in the local epidemiological context [48].

Despite the lack of large-scale prospective studies and based on the aforementioned facts, the KSCRH recommends vaccination for pregnant women and women taking COCs. The type and timing of the vaccine can be individualized according to the comorbidities and systemic conditions of the individuals. In women using COCs, discontinuation of COCs before or after vaccination does not appear to be necessary, and a delay in vaccination is not required. The risk of thrombosis does not appear to be high, regardless of the vaccination status, even if COCs are initiated. However, in women with risk factors for thrombosis who are planning contraception immediately after vaccination, use of LARCs, such as intrauterine or subcutaneous contraceptive implants, may minimize the risk of thrombosis.

\section{Conclusion}

The KSCRH recommends vaccination for young women because the benefits of vaccination outweigh the risks. In addition, the use of COCs does not require a delay in vaccination, and discontinuation of COCs is not necessary before or after vaccination. COCs also can be used safely in women with mild to moderate symptoms of confirmed or suspected COVID-19. However, women should stop taking COCs and consider using anticoagulants if they are severely ill with persistent symptoms of COVID-19. Considering that COVID-19 infection, COVID-19 vaccine, and COCs can all cause thrombotic complications, LARCs can be recommended because of its contraceptive effectiveness and safety.

\section{Conflict of interest}

No potential conflict of interest relevant to this article was reported.

\section{Ethical approval}

This study does not require approval of the Institutional Review Board because no patient data is contained in this article. The study was performed in accordance with the principles of the Declaration of Helsinki.

\section{Patient consent}

Written informed consent and the use of images from patients are not required for the publication.

\section{Funding information}

None.

\section{References}

1. World Health Organization. Pulse survey on continuity of essential health services during the COVID-19 pandemic: interim report, 27 August 2020 [Internet]. Geneva (CH): World Health Organization; c2020 [cited 2021 Sep 15]. Available from: https://www.who.int/publications/i/item/ WHO-2019-nCoV-EHS_continuity-survey-2020.1.

2. Bietsch K, Williamson J, Reeves M. Family planning during and after the West African Ebola crisis. Stud Fam Plann 2020;51:71-86.

3. Campbell AM. An increasing risk of family violence during the COVID-19 pandemic: strengthening community collaborations to save lives. Forensic Science International: Reports 2020;2:100089.

4. Cohen MA, Powell AM, Coleman JS, Keller JM, Livingston A, Anderson JR. Special ambulatory gynecologic considerations in the era of coronavirus disease 2019 (COVID-19) and implications for future practice. Am J Obstet Gynecol 2020;223:372-8.

5. Hanff TC, Mohareb AM, Giri J, Cohen JB, Chirinos JA. Thrombosis in COVID-19. Am J Hematol 2020;95:157889.

6. Middeldorp S, Coppens M, van Haaps TF, Foppen M, Vlaar AP, Müller MCA, et al. Incidence of venous thromboembolism in hospitalized patients with COVID-19. J 


\section{Obstetrics \& Gynecology Science}

Vol. 65, No. 2, 2022

Thromb Haemost 2020;18:1995-2002.

7. Tom S. Thrombosis with thrombocytopenia syndrome (TTS) following Janssen COVID-19 vaccine [Internet]. Atlanta (GA): Centers for Disease Control and Prevention; c2021 [cited 2021 Oct 10]. Available from: https:// www.cdc.gov/vaccines/acip/meetings/downloads/slides2021-04-23/03-COVID-Shimabukuro-508.pdf.

8. European Medicines Agency. VAXZEVRIA/COVID-19 Vaccine AstraZeneca: link between the vaccine and the occurrence of thrombosis in combination with thrombocytopenia [Internet]. Amsterdam (NL): European Medicines Agency; c2021 [cited 2021 Oct 10]. Available from: https://www.ema.europa.eu/en/documents/dhpc/directhealthcare-professional-communication-dhpc-vaxzevriapreviously-covid-19-vaccine-astrazeneca_en-0.pdf.

9. American Society of Reproductive Medicine. Patient management and clinical recommendations during the coronavirus (COVID-19) pandemic [Internet]. Birmingham (AL): ASRM; c2020 [cited 2021 Oct 10]. Available from: https://www.asrm.org/globalassets/asrm/asrmcontent/news-and-publications/covid-19/covidtaskforce. pdf.

10. European Society of Human Reproduction and Embryology. Coronavirus COVID-19: ESHRE statement on pregnancy and conception [Internet]. Strombeek-Bever (BE): ESHRE; c2021 [cited 2021 Oct 10]. Available from: https://www.eshre.eu/Europe/Position-statements/COVID19.

11. Lambalk C, van Wely M, Kirkegaard K, Williams A, de Geyter CJHR. Safety first-assisted human reproduction second. Human Reproduction 2020;35:741-2.

12. Stanley KE, Thomas E, Leaver M, Wells D. Coronavirus disease-19 and fertility: viral host entry protein expression in male and female reproductive tissues. Fertil Steril 2020;114:33-43.

13. Gonzalez DC, Khodamoradi K, Pai R, Guarch K, Connelly ZM, Ibrahim $E$, et al. A systematic review on the investigation of SARS-CoV-2 in Semen. Res Rep Urol 2020;12:615-21.

14. Kotlyar AM, Grechukhina O, Chen A, Popkhadze S, Grimshaw A, Tal O, et al. Vertical transmission of coronavirus disease 2019: a systematic review and metaanalysis. Am J Obstet Gynecol 2021;224:35-53.e3.

15. Veiga A, Gianaroli L, Ory S, Horton M, Feinberg E, Penzias A. Assisted reproduction and COVID-19: a joint statement of ASRM, ESHRE, and IFFS. Fertil Steril 2020;114:484-5.

16. World Health Organization. Report of a WHO technical consultation on birth spacing [Internet]. Geneva $(\mathrm{CH})$ : World Health Organization; c2021 [cited 2021 Oct 10]. Available from: https://apps.who.int/iris/bitstream/ handle/10665/69855/? sequence $=1$.

17. Makins A, Arulkumaran S; FIGO Contraception and Family Planning Committee. The negative impact of COVID-19 on contraception and sexual and reproductive health: could immediate postpartum LARCs be the solution? Int J Gynaecol Obstet 2020;150:141-3.

18. Curtis KM, Tepper NK, Jatlaoui TC, Berry-Bibee E, Horton LG, Zapata LB, et al. U.S. medical eligibility criteria for contraceptive USE, 2016. MMWR Recomm Rep 2016;65:1-103.

19. Centers for Disease Control and Prevention. Ensuring access to family planning Services during COVID-19: a summary of CDC's family planning recommendations for healthcare providers [Internet]. Atlanta (GA): CDC; c2020 [cited 2021 Sep 15]. Available from: https://www. cdc.gov/reproductivehealth/contraception/pdf/FP-andCovid-19-Fact-Sheet_Final.pdf.

20. van Hylckama Vlieg A, Helmerhorst FM, Vandenbroucke JP, Doggen CJ, Rosendaal FR. The venous thrombotic risk of oral contraceptives, effects of oestrogen dose and progestogen type: results of the MEGA case-control study. BMJ 2009;339:b2921.

21. Sidney S, Cheetham TC, Connell FA, Ouellet-Hellstrom R, Graham DJ, Davis D, et al. Recent combined hormonal contraceptives (CHCs) and the risk of thromboembolism and other cardiovascular events in new users. Contraception 2013;87:93-100.

22. Dinger J, Möhner S, Heinemann K. Cardiovascular risks associated with the use of drospirenone-containing combined oral contraceptives. Contraception 2016;93:37885.

23. Lidegaard $\varnothing$, Løkkegaard E, Jensen A, Skovlund CW, Keiding $\mathrm{N}$. Thrombotic stroke and myocardial infarction with hormonal contraception. N Engl J Med 2012;366: 2257-66.

24. Lidegaard $\varnothing$, Edström B, Kreiner S. Oral contraceptives and venous thromboembolism: a five-year national casecontrol study. Contraception 2002;65:187-96.

25. Dinger JC, Bardenheuer K, Assmann A. International 


\section{Obstetrics \& Gynecology Science}

Jae Hoon Lee, et al. Contraception in the COVID-19 pandemic

active surveillance study of women taking oral contraceptives (INAS-OC Study). BMC Med Res Methodol 2009;9:77.

26. Heinemann LA, Dinger JC. Range of published estimates of venous thromboembolism incidence in young women. Contraception 2007;75:328-36.

27. Servante J, Swallow G, Thornton JG, Myers B, Munireddy $S$, Malinowski AK, et al. Haemostatic and thromboembolic complications in pregnant women with COVID-19: a systematic review and critical analysis. BMC Pregnancy Childbirth 2021;21:108.

28. Rabinovich A, Abdul-Kadir R, Thachil J, Iba T, Othman M, Erez O. DIC in obstetrics: diagnostic score, highlights in management, and international registry-communication from the DIC and Women's Health SSCs of the International Society of Thrombosis and Haemostasis. J Thromb Haemost 2019;17:1562-6.

29. International Federation of Gynaecology and Obstetrics. FIGO committee on contraception and family planning statement on COVID-19 and pregnancy [Internet]. London (UK): FIGO; c2021 [cited 2021 Oct 10]. Available from: https://www.figo.org/covid-19-contraceptionfamily-planning.

30. Klok FA, Kruip MJHA, van der Meer NJM, Arbous MS, Gommers DAMPJ, Kant KM, et al. Incidence of thrombotic complications in critically ill ICU patients with COVID-19. Thromb Res 2020;191:145-7.

31. Oxley TJ, Mocco J, Majidi S, Kellner CP, Shoirah H, Singh $I P$, et al. Large-vessel stroke as a presenting feature of COVID-19 in the young. N Engl J Med 2020;382:e60.

32. Ramírez I, De la Viuda E, Baquedano L, Coronado P, Llaneza P, Mendoza N, et al. Managing thromboembolic risk with menopausal hormone therapy and hormonal contraception in the COVID-19 pandemic: recommendations from the Spanish Menopause Society, Sociedad Española de Ginecología y Obstetricia and Sociedad Española de trombosis y hemostasia. Maturitas 2020;137:5762.

33. Cagnacci A, Bonaccorsi G, Gambacciani M; board of the Italian Menopause Society. Reflections and recommendations on the COVID-19 pandemic: should hormone therapy be discontinued? Maturitas 2020;138:76-7.

34. Seeland U, Coluzzi F, Simmaco M, Mura C, Bourne PE, Heiland $M$, et al. Evidence for treatment with estradiol for women with SARS-CoV-2 infection. BMC Med
2020;18:369.

35. Lee JH, Kim YC, Cho SH, Lee J, You SC, Song YG, et al. Effect of sex hormones on coronavirus disease 2019: an analysis of 5,061 laboratory-confirmed cases in South Korea. Menopause 2020;27:1376-81.

36. Mauvais-Jarvis F, Klein SL, Levin ER. Estradiol, progesterone, immunomodulation, and COVID-19 outcomes. Endocrinology 2020;161:bqaa127.

37. Stelzig KE, Canepa-Escaro F, Schiliro M, Berdnikovs S, Prakash YS, Chiarella SE. Estrogen regulates the expression of SARS-COV-2 receptor ACE2 in differentiated airway epithelial cells. Am J Physiol Lung Cell Mol Physiol 2020;318:L1280-1.

38. Lippi G, Favaloro EJ. D-dimer is associated with severity of coronavirus disease 2019: a pooled analysis. Thromb Haemost 2020;120:876-8.

39. Tepper NK, Whiteman MK, Marchbanks PA, James AH, Curtis KM. Progestin-only contraception and thromboembolism: a systematic review. Contraception 2016;94: 678-700.

40. Lidegaard O, Nielsen LH, Skovlund CW, Løkkegaard E. Venous thrombosis in users of non-oral hormonal contraception: follow-up study, Denmark 2001-10. BMJ 2012;344:e2990.

41. Greinacher A, Thiele T, Warkentin TE, Weisser K, Kyrle PA, Eichinger S. Thrombotic thrombocytopenia after ChAdOx1 nCov-19 vaccination. N Engl J Med 2021;384:2092-101.

42. Muir KL, Kallam A, Koepsell SA, Gundabolu K. Thrombotic thrombocytopenia after Ad26.COV2.S vaccination. N Engl J Med 2021;384:1964-5.

43. Cushman M. Epidemiology and risk factors for venous thrombosis. Semin Hematol 2007;44:62-9.

44. Bonnar J. Coagulation effects of oral contraception. Am J Obstet Gynecol 1987;157(4 Pt 2):1042-8.

45. Oldenburg J, Klamroth R, Langer F, Albisetti M, von Auer $C$, Ay $C$, et al. Diagnosis and management of vaccinerelated thrombosis following AstraZeneca COVID-19 vaccination: guidance statement from the GTH. Hamostaseologie 2021;41:184-9.

46. Korea Centers for Disease Control and Prevention. Vaccination in pregnant women [Internet]. Osong (KR): Korea Centers for Disease Control and Prevention; c2021 [cited 2021 Oct 10]. Available from: http://kdca.go.kr/ board/board.es? $\mathrm{mid}=a 20501010000 \& \mathrm{bid}=0015 \&$ act 


\section{Obstetrics \& Gynecology Science}

Vol. 65, No. 2, 2022

=view\&list_no=717155.

47. Centers for Disease Control and Prevention. COVID-19 vaccines while pregnant or breastfeeding [Internet]. Atlanta (GA): CDC; c2021 [cited 2021 Oct 11]. Available from: https://www.cdc.gov/coronavirus/2019-ncov/vaccines/recommendations/pregnancy.html.

48. World Health Organization. Update on WHO interim recommendations on COVID-19 vaccination of pregnant and lactating women [Internet]. Geneva $(\mathrm{CH})$ : World Health Organization; c2021 [cited 2021 Oct 10]. Available from: https://cdn.who.int/media/docs/ default-source/2021-dha-docs/update-on-who-interimrecommendations-on-c-19-vaccination-for-pregnantand-lactating-women-70-.pdf. 